\title{
Thirty Nine
}

National Cancer Institute

\section{Source}

National Cancer Institute. Thirty Nine. NCI Thesaurus. Code C105798.

A natural number greater than thirty-eight and less than forty and the quantity that it denotes. 